\title{
Pathology of natural Francisella tularensis subsp. holarctica infection in two yellow-necked mice (Apodemus flavicollis)
}

\author{
Gete Hestvik ${ }^{1,2^{*}}$, Henrik Uhlhorn², Roland Mattsson², Eva Westergren², Fredrik Södersten ${ }^{1}$, Sara Åkerström ${ }^{3}$ \\ and Dolores Gavier-Widén ${ }^{1,2}$
}

\begin{abstract}
Background: Tularemia is a zoonosis caused by the bacterium Francisella tularensis. It has a wide host range, which includes mammals, birds and invertebrates. F. tularensis has often been isolated from various species of small rodents, but the pathology in naturally infected wild rodent species has rarely been reported.

Case presentation: Herein, we describe the pathology of tularemia in two naturally infected wild yellow-necked mice (Apodemus flavicollis). To visualize F. tularensis subsp. holarctica, indirect immunofluorescence and immunohistochemistry were applied on tissue sections. Real time polymerase chain reaction detected the bacterium in samples from liver and spleen in both mice. The only finding at necropsy was splenomegaly in one of the mice. Histological examination revealed necrotic foci in the liver associated with mild inflammation in both mice. Immunohistochemistry and indirect immunofluorescence showed bacteria disseminated in many organs, in the cytoplasm of macrophages, and intravascularly.

Conclusions: The two yellow-necked mice died of an acute disease caused by tularemic infection disseminated to many organs. Further investigations of naturally infected small rodents are important to better understand the variability in pathological presentation caused by infection by F. tularensis subsp. holarctica, as well to elucidate the importance of small rodents as transmitters and/or reservoirs.
\end{abstract}

Keywords: Apodemus flavicollis, Francisella, Immunohistochemistry, Pathology, Tularemia, Small rodent, Yellownecked mouse

\section{Background}

Tularemia is a zoonotic infectious disease caused by the bacterium Francisella tularensis. F. tularensis has several subspecies, but only $F$. tularensis subsp. holarctica on the Northern Hemisphere, and F. tularensis subsp. tularensis, in North America, are known to cause disease [1]. F. tularensis subsp. tularensis is more virulent, causing more severe disease compared to subsp. holarctica. The bacterium has a wide host range, including mammals, birds and invertebrates [2, 3]. The severity of disease upon infection varies between species. For

\footnotetext{
*Correspondence: gete.hestvik@sva.se

${ }^{2}$ Department of Pathology and Wildlife Diseases, National Veterinary

Institute (SVA), 75189 Uppsala, Sweden

Full list of author information is available at the end of the article
}

example, many small rodent species, such as Apodemus spp. and mountain hares (Lepus timidus) contract an acute, severe disease rapidly leading to death while carnivores are quite resistant and develop no or mild disease [4]. Infection with $F$. tularensis occurs through direct contact with infected tissues and fluids, via mucous membranes, inhalation and ingestion. Indirect infection is common, through bites from arthropod vectors, in particular mosquitoes, biting flies, and ticks. [5]. Tularemia is endemic in parts of Sweden, frequently affecting mountain hares and European brown hares (Lepus europaeus) [6]. There are several studies regarding detection of $F$. tularensis in organs and seroprevalence in wild small rodents in the former Soviet Union and Europe [7, 8], but publications of 
pathological manifestations in wild rodents are scarce. The pathology in small rodents has been investigated in experimental infections with $F$. tularensis subsp. holarctica [9-11], but studies of the pathology in naturally infected wild small rodents are few. One study describes the pathology in field voles (Microtus agrestis) in Finland, and another the pathology in house mice (Mus musculus domesticus) in Switzerland [11, 12]. Here we describe the pathology in two naturally infected yellow-necked mice (Apodemus flavicollis).

\section{Case presentation}

Two adult male yellow-necked mice found dead in a courtyard in Södertälje, central-eastern Sweden, in September 2010 were sent to the National Veterinary Institute (SVA) for necropsy.

To detect $F$. tularensis subsp. holarctica, quantitative real time polymerase chain reaction (qPCR) was applied on swab samples from liver and spleen pooled for each mouse separately. Tissue samples were swabbed using sterile cotton swabs, a sampling method used for routine diagnostics for many years at our laboratory. The swabs were incubated in $570 \mu \mathrm{L} \mathrm{G} 2$ buffer and $30 \mu \mathrm{L}$ proteinase K solution (EZ1 Tissue DNA Extraction Kit) (Qiagen, Sollentuna, Sweden) at $56{ }^{\circ} \mathrm{C}$ for 15 min under continuous agitation followed by incubation at $95^{\circ} \mathrm{C}$ also under continuous agitation for $15 \mathrm{~min}$. An EZ1 Tissue DNA Extraction Kit and the EZ1 Advanced Instrument (with the Bacteria Card) (Qiagen, Sollentuna, Sweden) was used for extracting DNA. For the DNA extraction, $195 \mu \mathrm{L}$ of the above lysate plus $5 \mu \mathrm{L}$ of internal positive control (IPC, virions from seal herpes) were used. The extracted DNA was eluted in $50 \mu \mathrm{L}$ elution buffer, and $2 \mu \mathrm{L}$ of the $50 \mu \mathrm{L}$ elution buffer was used as template for the qPCR. The qPCR was based on a specific point mutation, SNP, which are inherited in the strains belonging to F. tularensis subsp. holarctica. The primers used for target FtB15 were following, FtB15-F: CCATCAGCAGTAGTATAA CCACCAA, FtB15-R: TGGCGCAGATATGACTAA AGTC. Probe for FtB15: TATTACTAGGAATGGCGC GC (FAM-MGB). The primers used for the internal positive control (IPC) were following, IPC-F: GGGCGAATC ACAGATTGAATC, IPC-R: GCGGTTCCAAACGTA CCAA, probe: TTTTTATGTGTCCGCCACCATCTG GATC (Cy5-Taqman probe BHQ-2). As a positive control we used DNA from a $F$. tularensis subsp. holarctia type B strain FSC200. A 45 cycle qPCR fast program was used.

At necropsy, tissue samples from liver, spleen, kidney, lung and heart were fixed in $10 \%$ neutral buffered formalin and routinely processed for histopathology. Tissue sections were cut at $4 \mu \mathrm{m}$ and stained with hematoxylin and eosin (HE).
To detect and visualize $F$. tularensis in tissue sections, indirect immunofluorescence (IIF) and immunohistochemistry (IHC) were applied.

IIF, a method previously used in routine diagnostics at SVA, was performed on direct smears of bone marrow, and on unstained formalin fixed tissue sections of liver, spleen, lung and kidney, applying an in-house $F$. tularensis-positive rabbit serum (polyclonal antibodies) (SVA, Uppsala, Sweden) for detection. Sections were incubated in a $37{ }^{\circ} \mathrm{C}$ moist-chamber for $30 \mathrm{~min}$ with the rabbit primary polyclonal antibody diluted 1:20 in $0.05 \mathrm{M}$ phosphate buffer, pH 7.9 (PBS). After rinsing the slides in PBS, a secondary fluorescein-labeled goat anti-rabbit $\operatorname{IgG}(\mathrm{H}+\mathrm{L})$ (Vector, Laboratories, Burlingame, CA, USA) diluted 1:20 in PBS was applied. The slides were incubated in a $37^{\circ} \mathrm{C}$ moist-chamber for $30 \mathrm{~min}$, rinsed in PBS and mounted with a cover glass and phosphate-buffered glycerol, $\mathrm{pH}$ 8.6. To exclude false negative staining, sections of liver and spleen from an experimentally infected laboratory mouse was examined in the same way. To exclude false positive staining, serum from a known tularemia-negative rabbit was used as primary antibody. The slides were examined in a fluorescence microscope, excitation at $490 \mathrm{~nm}$ and emission at $530 \mathrm{~nm}$. Bright green fluorescence and a morphology consistent with the bacterium was considered as positive.

IHC was performed on sections from all histopathologically examined organs using a mouse primary monoclonal antibody, FB11 (Meridian Life Science Inc., Nordic Biosite AB, Täby, Sweden) directed against $F$. tularensis lipopolysaccharide antigen. To enable detection of $F$. tularensis in mouse tissue using a mouse primary antibody, Vector ${ }^{\circledR}$ M.O.M $M^{\mathrm{TM}}$ (Vector Laboratories) was also applied to reduce endogenous mouse Ig staining. Sections were incubated in the primary antibody diluted in M.O.M Diluent at 1:3000 for $30 \mathrm{~min}$, followed by incubation in a working solution of M.O.M. biotinylated AntiMouse Ig Reagent for $10 \mathrm{~min}$. The detection system used was VECTASTAIN ${ }^{\circledR}$ elite ABC standard kit (Vector Laboratories,), together with the peroxidase substrate $\mathrm{DAB}$ (Dako, Agilent, Glostrup, Denmark). Counterstaining was performed with Mayer's hematoxylin. A serial parallel section of each IHC-tested section was incubated with $2 \%$ bovine serum albumin (BSA) instead of the primary antibody, which served as a primary antibody-omit negative control. A known tularemia-positive liver sample from a European brown hare, in which $F$. tularensis subsp. holarctica previously had been detected by q-PCR, was included as positive control.

The two yellow-necked mice were in poor body condition and had marked postmortem changes. Apart from slight splenomegaly in one mouse, no other gross changes were observed. Histological examination 


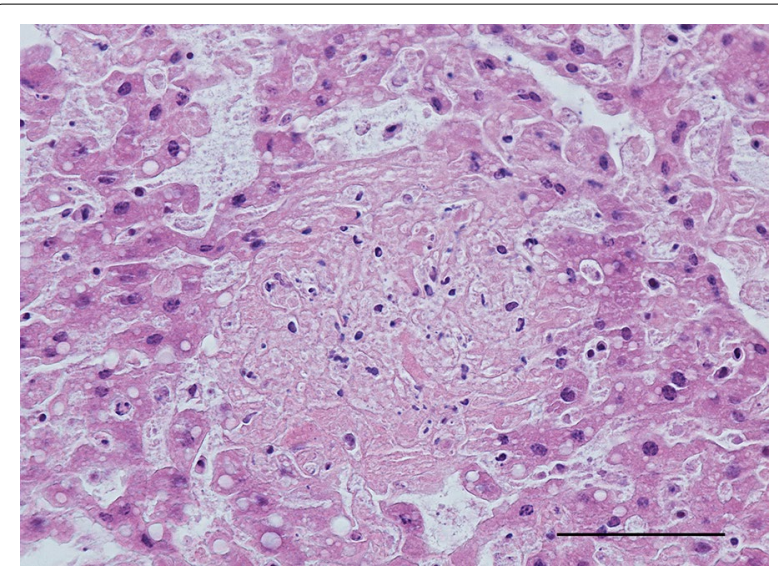

Fig. 1 Photomicrograph showing liquefactive necrosis in the liver. Nuclear debris is seen as dark basophilic granules in the lesion. Yellow-necked mouse, HE. Bar $=100 \mu \mathrm{m}$ revealed numerous necrotic foci in the liver in one mouse and few in the other (Fig. 1). Some of the necroses were coagulative showing necrotic hepatocytes with preserved architecture in the periphery of lesions, but most were lytic. Mild infiltration of lymphocytes, plasma cells and macrophages was seen in association to the necrotic areas, and lymphocytes could also be seen in the sinusoids. Autolysis was severe in the spleens, but there was a strong suspicion of necrosis. In one mouse, pulmonary alveolar septa were moderately to markedly thickened and multifocally consolidated by lymphocytes, plasma cells, macrophages and a few heterophils. Multifocal necrosis scattered in the inflamed tissue was suspected but was difficult to assess with certainty because of autolysis. No histopathological changes could be seen in the heart or kidney. IIF showed bacteria disseminated in liver, spleen, bone marrow, lung and kidney, in lesions or intravascularly (Figs. 2a, 3a). IHC visualized F. tularensis intravascularly in glomerular capillaries and interstitial blood vessels in the kidney, in liver sinusoids, and in larger vessels in the liver and heart. In the lung, bacteria were detected in the cytoplasm of alveolar macrophages as well as in pneumocytes, alveolar septal capillaries and larger blood vessels (Figs. 2b, 3b). qPCR detected F. tularensis subsp. holarctica in pooled samples from the liver and spleen in both mice. The compiled result show that both mice died of acute disseminated septic tularemia.

\section{Discussion and conclusions}

The pathological findings in the yellow-necked mice were similar to those described in studies of laboratory mice [9], wild common hamsters (Cricetus cricetus) [10], and field and bank voles (Myodes glareolus) [11], all experimentally infected with $F$. tularensis subsp. holarctica.
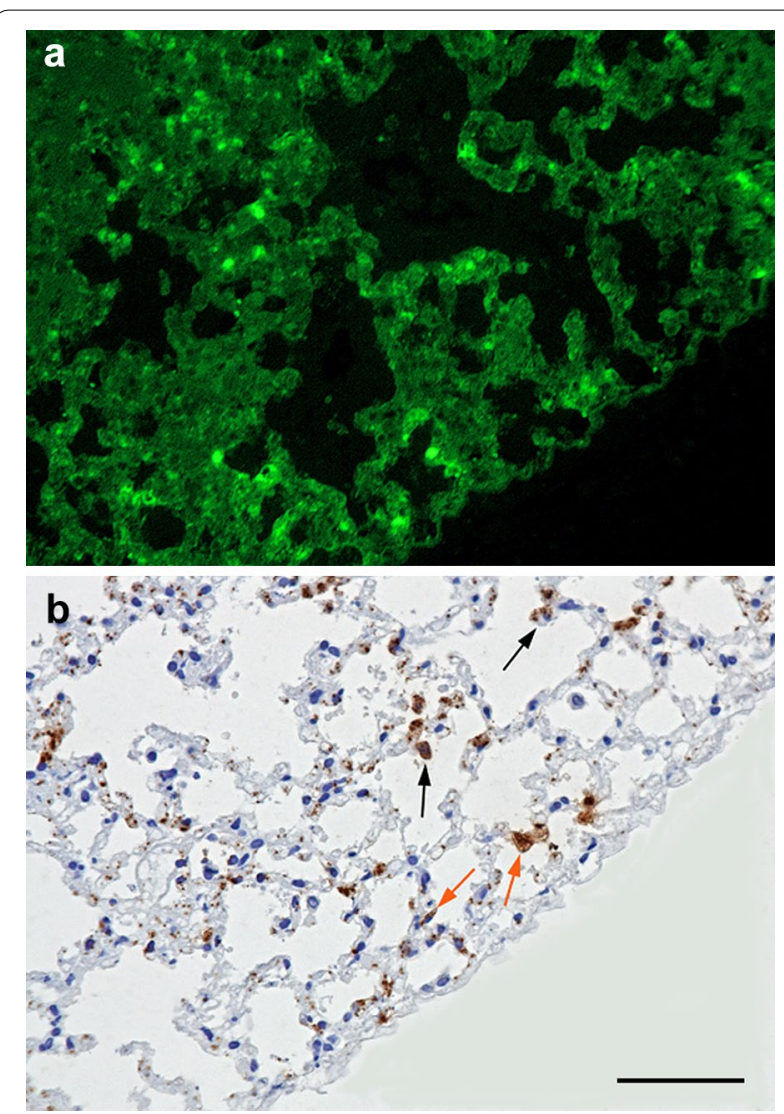

Fig. 2 Microcopic visualization of F. tularensis in the lung of a yellow-necked mouse. a Indirect immunofluorescence photomicrograph of the lung infected by F. tularensis. F. tularensis bacteria are visualized in bright green fluorescence in the alveolar septa. $\mathbf{b}$ Immunohistochemistry for F. tularensis of the same area shown in a reveals their presence in the cytoplasm of pneumocytes (orange arrow) and alveolar macrophages (black arrow).

Yellow-necked mouse. Bar $=100 \mu \mathrm{m}$

Gross lesions reported in laboratory mice were enlarged spleens and mottled, pale livers. Microscopically, necrosis was evident in the organs examined; spleen, liver and lung. The only gross lesions in the hamsters were enlarged spleens with grossly visible necrosis. In the voles, no gross changes were found. In hamsters, field and bank voles, histopathology showed necroses in spleen, liver, bone marrow and lymph nodes. The hamsters also had acute nephrosis and interstitial bronchopneumonia. IHC revealed $F$. tularensis intravascularly in several organs of the hamsters and voles.

In a study of naturally infected wild field voles [11], extensive necrosis was evident in the spleen, whereas in the liver only single cell necrosis was seen. Bacteria were found in vessels and capillaries of the lung, liver, spleen and kidney, shown by IHC. In naturally infected 


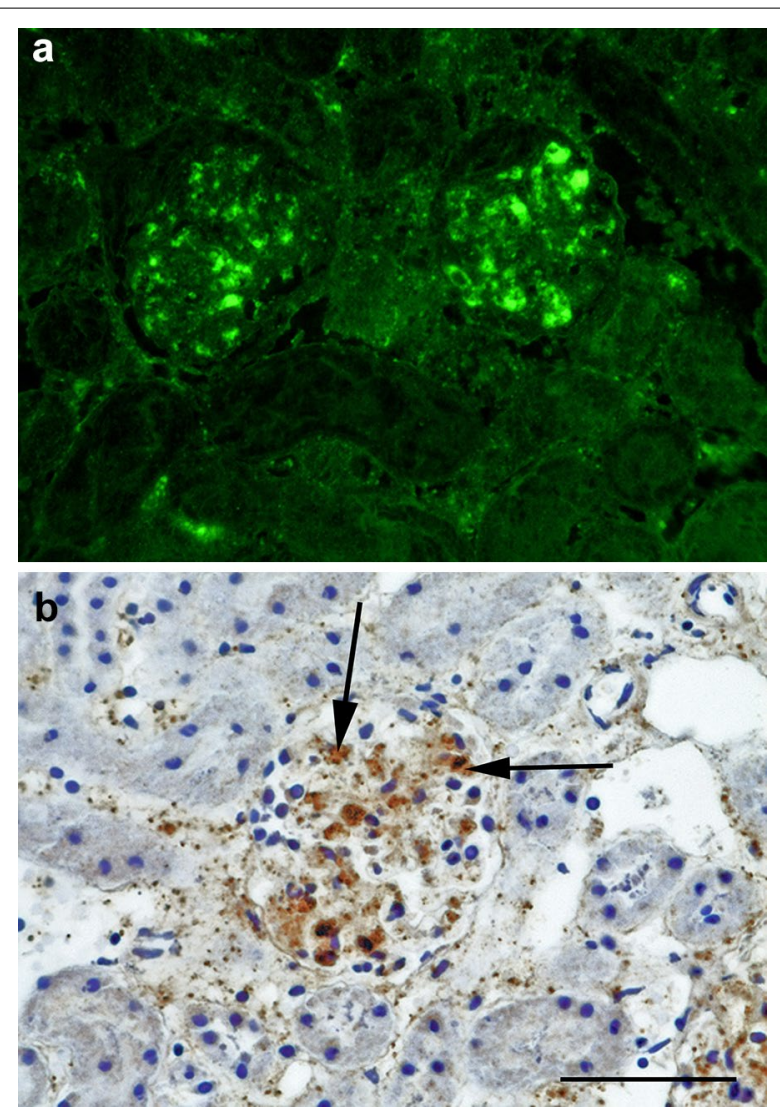

Fig. 3 Indirect immunofluorescence photomicrograph of a kidney infected by F. tularensis. a Indirect immunofluorescence showing F. tularensis (bright green fluorescence) in the glomeruli. b Immunohistochemistry showing the location of the bacteria in glomerular capillaries (black arrow). Yellow-necked mouse. Bar $=50 \mu \mathrm{m}$

free-ranging house mice in Switzerland, necrosis in spleen, liver and lung were found. The lung lesions had variable degree of severity [12].

In the literature, it is frequently discussed whether small rodent species die of acute disease or if they may act as reservoirs or transmitters of the bacteria. The term rodents refer to mammals of the order Rodentia, which is the greatest diversified mammalian order, containing $40 \%$ of all mammal species inhabiting a broad range of different habitats [13]. There is a high diversity of biological characteristics among the rodent species, and therefore the sensitivity to develop disease might differ between them [14]. The majority of studies performed on wild small rodents have been limited to detection of F. tularensis in organs and/or of antibodies but have not included reports of pathology.

The two yellow-necked mice included in our study were in poor body condition, had necroses and mild inflammation in several organs, as well as intravascular bacteria. The mice survived long enough to develop subacute lesions and probably died of sepsis. The very limited existing data on the pathobiology of the infection makes it difficult to assess the epidemiological role of small rodents as, for example, possible natural reservoirs and transmitters of $F$. tularensis subsp. holarctica. The knowledge gaps of natural infection in small rodents include the range and variability in clinicopathological presentation and the distribution and abundance of bacteria in organs and excretions to asses shedding patterns. Potentially, chronically infected small rodents could act as spreaders or carriers of infection, but such a chronic form of infection has not yet been reported. Nonetheless, several small rodent species, such as lemmings (Lemmus spp.), house mice, yellow-necked mice and black rats (Rattus rattus) have been implicated in the epidemiology of tularemia in humans and animals $[15,16]$. For example, oropharyngeal tularemia has been attributed to consumption of water from water wells contaminated by tularemic lemmings [16] and pneumonic forms of tularemia to inhalation of hay contaminated by tularemic rodents [17]. More investigations on the pathobiology of natural tularemia infection in rodents is warranted to provide information on organ lesions and shedding patterns, and to investigate the role of wild small rodents as potential transmitters and/or reservoirs.

\section{Authors' contributions \\ GH necropsied and assessed the histopathology and immunohistochemistry, and drafted the manuscript. HU participated in the assessment of histopa- thology and immunohistochemistry and contributed to the writing of the manuscript. RM performed and assessed the indirect immunofluorescence, and contributed to the writing of the manuscript. EW performed the histo- pathology and immunohistochemistry, contributed to the assessment of the immunohistochemistry and contributed to the writing of the manuscript. FS participated in the assessment of histopathology and immunohistochemistry and contributed to the writing of the manuscript. SA was responsible for the qPCR and contributed to the writing of the manuscript. DGW partici- pated in the assessment of histopathology and immunohistochemistry and contributed to the writing of the manuscript. All authors criticized the final manuscript. All authors read and approved the final manuscript.}

\section{Author details \\ ${ }^{1}$ Department of Biomedical Sciences and Veterinary Public Health, Faculty of Veterinary Medicine and Animal Sciences, Swedish University of Agricultural Sciences (SLU), P.O. Box 7028, 75007 Uppsala, Sweden. ${ }^{2}$ Department of Pathol- ogy and Wildlife Diseases, National Veterinary Institute (SVA), 75189 Uppsala, Sweden. ${ }^{3}$ Department of Microbiology, National Veterinary Institute (SVA) 75189 Uppsala, Sweden.}

\section{Competing interests}

The authors declare that they have no competing interests.

Availability of data and materials

Not applicable.

\section{Consent for publication}

Not applicable.

Ethics approval and consent to participate

Not applicable. 


\section{Funding}

No funding was received for this study.

\section{Publisher's Note}

Springer Nature remains neutral with regard to jurisdictional claims in published maps and institutional affiliations.

Received: 13 October 2017 Accepted: 25 April 2018

Published online: 02 May 2018

\section{References}

1. Keim P, Johansson A, Wagner DM. Molecular epidemiology, evolution, and ecology of Francisella. Francisella tularensis: biology, pathogenicity, epidemiology, and biodefense. Ann NY Acad Sci. 2007;1 105:30-66.

2. Pfahler-Jung K. Die globale Verbreitungen der tularemie (Global distribution of tularaemia). Ph.D. dissertation, Justus-Liebig University, Giessen. Berlin: Duncker \& Humblot;1989.

3. Morner T, Addison E. Tularemia. In: Williams ES, Barker IK, editors. Infectious diseases of wild animals. Ames: Iowa State University Press; 2001. p. 301-2.

4. Sjostedt A. Epidemiology. In: Tarnvik A, editor. WHO guidelines on tularaemia. Geneva: WHO Press; 2007. p. 5-10.

5. Ellis J, Oyston PCF, Green M, Titball RW. Tularemia. Clin Microbiol Rev. 2002;15:631-46.

6. Morner T, Sandstrom G, Mattsson R, Nilsson P. Infections with Francisella tularensis biovar palaearctica in hare (Lepus timidus, Lepus europaeus) from Sweden. J Wildl Dis. 1988;24:422-33.

7. Olsufjev NG. Tularemia. In: Pavlovsky YN, editor. Human diseases with natural foci. Moscow: Foreign languages publishing house; 1963. p. 219-81.
8. Hestvik G, Warns-Petit E, Smith LA, Fox NJ, Uhlhorn H, Artois M, et al. The status of tularemia in Europe in a one-health context: a review. Epidemiol Infect. 2015;143:2137-60.

9. Conlan JW, Chen WX, Shen H, Webb A, KuoLee R. Experimental tularemia in mice challenged by aerosol or intradermally with virulent strains of Francisella tularensis: bacteriologic and histopathologic studies. Microb Pathog. 2003:34:239-48.

10. Gyuranecz M, Denes B, Dan A, Rigo K, Foldvari G, Szeredi L, et al. Susceptibility of the common hamster (Cricetus cricetus) to Francisella tularensis and its effect on the epizootiology of tularemia in an area where both are endemic. J Wildl Dis. 2010;46:1316-20.

11. Rossow H, Forbes KM, Tarkka E, Kinnunen PM, Hemmilä H, Huitu O, et al. Experimental infection of voles with Francisella tularensis indicates their amplification role in tularemia outbreaks. PLOS ONE. 2014;9:1-9.

12. Origgi FC, Koenig B, Lindholm AK, Mayor D, Pilo P. Tularemia among freeranging mice without infection of exposed humans, Switzerland, 2012. Emerg Infect Dis. 2015;21:133-5.

13. Blashfield JF. Rodents. In: Science encyclopedia. http://science.jrank.org/ pages/5920/Rodents.html. Accessed 12 Sept 2017.

14. Sjostedt A. Tularemia: history, epidemiology, pathogen physiology, and clinical manifestations. Ann N Y Acad Sci. 2007;1105:1-29.

15. Reintjes R, Dedushaj I, Gjini A, Jorgensen TR, Cotter B, Lieftucht A, et al. Tularemia outbreak investigation in Kosovo: case control and environmental studies. Emerg Infect Dis. 2002;8:69-73.

16. Larssen KW, Afset JE, Heier BT, Krogh T, Handeland K, Vikoren T, et al. Outbreak of tularaemia in central Norway, January to March 2011. Euro Surveill. 2011:16:2-4.

17. Syrjala H, Kujala P, Myllyla V, Salminen A. Airborne transmission of tularemia in farmers. Scand J Infect Dis. 1985:17:371-5.
Ready to submit your research? Choose BMC and benefit from:

- fast, convenient online submission

- thorough peer review by experienced researchers in your field

- rapid publication on acceptance

- support for research data, including large and complex data types

- gold Open Access which fosters wider collaboration and increased citations

- maximum visibility for your research: over $100 \mathrm{M}$ website views per year

At BMC, research is always in progress.

Learn more biomedcentral.com/submissions 